\title{
Psychosocial factors that influence marital couple duration
}

\author{
Mihaela Luminița Sandu \\ Ovidius University of Constanta - Faculty of Psychology and Educational Sciences \\ mihaela_naidin@yahoo.com
}

\begin{abstract}
Claudia Salceanu
Ovidius University of Constanta - Faculty of Psychology and Educational Sciences

claudiasalceanu@yahoo.com
\end{abstract}

\begin{abstract}
Humanity's history, with its biological, psychological, social, cultural, economic and political dimensions, belongs to the coexistence of man and woman, to the relationships between them and their children. In time, family has become one of the oldest community forms, which ensures the evolution and continuity of the human species. Family influences the most the human being. Many studies made by researchers in this field, have proved the importance of the family for people, emphasizing that family is a real laboratory for the development of a person. In contemporary society, family suffered a lot of important transformations, like female empowerment for example, which, in turn, has determined many other changes in the family life. Due to these changes, the marital couple is currently more interested in satisfying its own interests and minimizes the tasks that society assigns to the family. A sample of 30 married couples, residing in Constanta County, has been assessed with Kansas Marital Satisfaction Scale, Locke-Wallace Marital Adjustment Scale, Kansas Marital Conflict Scale and Influence of the Material Situation on the Couple Questionnaire. The main objective of the research was to identify the relationship between these factors and the duration of the marital couple. We identified significant correlation between: (1) the couple's duration and marital satisfaction; (2) the marital satisfaction and marital adjustment; (3) the level of the financial status and marital quarrels. Results are discussed in terms of marital counseling, the increase of marital satisfaction and the development of assistance for families in need.
\end{abstract}

Keywords. marital satisfaction, financial status, couple, conflict, couple's duration, marital adjustment

\section{Introduction}

Due to the fact that family experiences awake different types of emotions, both social philosophers and psychologists believe that the family is the main element in the social structure, and thus, this field has attracted ideologists and theorists as well.

The duration, satisfaction and stability of the marital couple in today's society are no longer influenced by the same psychological and social factors as in the past. In time, the 
modern family took over the place of the traditional family, this being characterized by a flexible structure of authority and power.

The number of divorces has increased considerably in recent years (https://www.international-divorce.com/romania_divorce.htm). The simplification of the divorce process, the metamorphoses of the sex roles, the emancipation of the woman and her financial independence were the main factors that determined the increase in the number of divorces.

Following the research conducted on couples, it was found that dissatisfaction, conflicts, infidelity, family violence or poor financial situation are the main reasons leading to divorce (Hooker, 2013). For society, divorce constitutes a democratic resolution of citizens' wishes, a possibility to avoid the traumas of couples with conflicting relationships and to avoid the educational dysfunctions of such relationships on the minor children and the possibility of establishing normal, functional couples. But ensuring the stability of families, decreasing the number of divorces, avoiding the social consequences of the couples' instability is a difficult task to achieve.

That is why the issue of marital couples implies a broad investigation of the factors that influence both their stability and instability. In order to intervene on the phenomenon of family dissolution, it is necessary to know the factors that influence it, those that lead to dissolution, failure, but also those that strengthen a family and ensure the success of its operation. The role of social services and social workers is to intervene in order to avoid divorce, or in case of its imminence, to minimize its negative effects on the persons involved and on society.

The experience of a divorce can be quite traumatic not only for the people involved, but also for the children, relatives, or friends.

Children are also very affected by divorce, both psychologically and socially. In most cases, with the divorce, financial problems also appear. Also, numerous researches (Anderson, 2014) have revealed that quite a large percentage of the number of offenders and drug users is represented by persons from disorganized families. Parental divorce, family restructuring and the emergence of a step-parent often cause behavioral deviations with consequences for the rest of the life: aggression, delinquency, early sex life, school dropout.

Only after the fall of communism could we talk about social services in the true sense of the word. Family issues were not one of the concerns of the old regime. Only in recent years, family problems have been the subject of public debates that are among the priorities of action. The idea of marriage counseling is no longer so foreign to Romanians. However, it is found that at the local level, within the Public Social Assistance Services there is an acute lack of social assistance services for these types of problems. One of the causes would be the lack of specialists in the field, as well as the insufficient local budgets to ensure this approach.

Through the university training of social workers, the family issues can know new strategies of approach and settlement. But a first stage of problem solving is knowing the factors that determine their occurrence, which is why in this paper we intend to approach the psychosocial factors that influence the duration of the marital couple.

From this perspective, the present paper, structured in two parts, the first with theoretical views and the second with experimental arguments aim to evaluate and identify the factors that influence family life.

\section{Marital Couple / Family}

The analysis of couples reveals multiple aspects, particularly complex and specific, but which are nevertheless treated unequally and with too much ease by specialists, their study 
being limited to its formal aspects. The couple as stable association of partners, as understood and accepted today, has a long and interesting personal history. „It is the result of the recognition and enhancement of a specific human relationship, established over time, and its beginnings correspond to the first stages of human history" (Enăchescu, 2003): The idea of family appears rather late in the evolution of humanity, with the establishment of the relations of kinship between the individuals that are linked by a common biological origin.

Mitrofan (1989) in her book "The conjugal couple: Harmony and disharmony", asserts that "The family is the nucleus of human organization, the molecule or microstructure which, in a small way, realizes all the functions of society, as a great system: the reproduction and assurance of the biological continuity of the human species, the production of livelihoods, the education and socialization of the newborns and, thus, the ensuring of the moral-spiritual continuity of society".

The American sociologists, Burgess, Locke and Thomas (2004) claimed that family differs from the other social groups by the following characteristics: it is formed by persons united by marriage, blood, adoption; the members usually live under the same roof, forming a single household; it is composed of people who interact, inter-communicate within the roles of husband-wife, father-mother, supporting and perpetuating a common culture. But this definition raises some issues, as George Neamtu notes (2004): "There may be the situation of the biological father's non-recognition, of the father's non-existence: there may also be cases where, without prior divorce, there are couples formed by partners who each comes from a different relationship, and who, in the new couple, give birth and raise children along with the children brought in from previous relations. So these structural definitions risk setting aside groups of people who call themselves family and have a life organized as a family." (Neamţu, 2004).

Hartman and Laird (1983) adopt a phenomenological definition of the family stating that: "A family becomes a family when two or more individuals decide that they form a family, which means that, at the moment they live together, they develop an intimacy in which they share their emotional needs of vicinity, of living in a space they call their home where they define the roles and tasks in order to meet the biological, social and psychological needs of the individuals involved.." (Neamţu, 2004).

The French anthropologist Claude Levi Strauss (1973) defines family as: "That social group that originates from the marriage, consists of the husband, wife and the children born out of their relationship (where other relatives can be added), united by rights and obligations of a moral, legal, economic, religious and social nature, including the sexual ones as well.” (Neamţu, 2004).

Marry Ann Laman and Riedman Agnes ("Marriage and family") start from the analysis of a definition that is in circulation in the USA: "Family is a group of people united by marriage, blood, adoption which: constitute a single home, interact and communicate with each other in accordance with their respective social roles, create and maintain a common culture" (Neamţu, 2004).

The Canadian "Vanier" Family Institute defines the term family as: "The family is defined as any combination of two or more persons, who in time relate through mutual agreement, birth and / or adoption or placement, and who jointly assume responsibilities of the following type: physical support and caring for group members, adding of new members through procreation and adoption, socialization of children, social control of children, production, consumption and distribution of goods and services, affective feed - love" (Laman, Riedman, 2005).

Jean Baechler in "Groups and sociability" argues that although the couple is the smallest group possible, for comparative sociology this is not a truism but an exception. Two 
model couples historically claim the right to represent the smallest group possible: either the nuclear family or the extended / enlarged family. In both cases, the basic cell is the family, so not the couple who is not represented and felt only as an instrument of a purpose that surpasses it. Everywhere the marriage causes one of the main social rites along with birth, puberty and death (Vanier Institute, p. 13). Family represents "a union of personal interactions and intercommunications, comprising the social roles of husband, wife, father, mother, son, brother, sister constituted in and through mutual, shared affection" (Baechler, 2005). From a psychological point of view, family is defined as: ,, social institution based on the mutual choice of the marital partners in order to ensure the reproduction of the species, under determined socio-cultural conditions" (Mitrofan, 1989). Moreover, marriage is defined from a sociological point of view as representing a , socially accepted way by which two or more persons constitute a family. It may involve a legal aspect and a religious aspect" (Popescu-Neveanu, 1978).

\section{Traditional/modern family characteristics}

The history of humanity, analyzed from a biological, psychological, economic and sociocultural perspective, belongs entirely to the family, the man, the woman and the relationships between them.

Families in contemporary society have undergone many transformations in recent decades. Due to the changes that have taken place within the family, even now the term family has become ambiguous and sometimes difficult to define. The family tends to cover today completely different realities from those characteristic of previous generations. The functions of the family have also undergone many transformations: the socialization function is shared with different institutions that have taken over parental responsibilities, the emancipation of the woman and her access to studies has led to the modification of the relations between spouses, the domestic obligations of the woman being neglected in favor of the career.

By comparing the traditional family with the modern family today we can distinguish some clear characteristics of each.

The modern family is different from the traditional family: loyalty to the family is reduced in favor of self-interest, the woman is no longer subordinate as wife and mother. As I. Mitrofan and Ciuperca said "The traditional family operates under the authority of the oldest adult male - pater familia" (Mitrofan, 2002).

In contrast to the traditional family where authority was the focal value, cooperation in the modern family is more valued. Other values such as equality, change, communication are supported. There is no longer that unique, dominant model, where the man decides. The modern relationship captures the reciprocity of power and authority, on different levels and different intensities, in the more general context of an affirmed and increasingly applied egalitarianism.

Mihaescu and Voinea (2008) consider that the family has lost much of its character as a social institution, the family couple being more interested in satisfying their own interests and less in carrying out the functions that the society assigns to the family institution.

\section{Psychosocial factors of functionality and marital stability}

According to Rodica Enache (2008), "the harmonization and stabilization of the conjugal union is based on the plastic capacity of modifying and correcting the role behavior, as much as possible in accordance with the expectations and the mutual-projected needs in the dyad".

The level and quality of the partnership needs act as a true "motivational key" for each partner. The possibilities of mutual satisfaction of these needs decide ultimately the course of the interpersonal relationship, the maintenance, the amplification, the diminution or the 
alteration of love feelings that link the two partners. The assignments, concessions, metamorphoses of the role behaviors in meeting these vital needs, require a flexible availability of interpersonal adaptation, of interrelational creativity, a certain level of ability for partnership. This constitutes the individual capacity of interpersonal, creative and flexible adaptation, expressed through the conduct of marital role, as a behavioral model with stabilizing value in the functioning of the couple. Having as a starting and reference point, the models of conjugal role known in childhood, in the family of his/her parents, the married adult reconstructs and develops his/her personality through his/her own conjugal and parental role. The conjugal role is continually perfected in conjugal interactions throughout marriage. The mutual satisfaction of the partnership systems in all its aspects (as a conjugal and parental role) gives the marriage durability and meaning, ensuring the physical and mental balance of the partners.

„We consider that a certain correspondence and consensus on the level of ideas, attitudes and aspirations on the one hand, and on the level of communication and erotic-sexual and procreative behavior, on the other hand, is the essential element of marital success, stability and satisfaction". (Mihăescu, Voinea, 2008).

"Marital adaptation aims at restructuring both at the level of marital role behavior of individuals and at the level of their interpersonal functionality" (Mitrofan, Mitrofan, 1996). At the individual level, it implies successive, dynamic orientations, enhancements, activations and reorientations of the partnership motivations (biological-sexual, socio-affective, self-realization and self-development of the personality), as well as of the partnership availability, essentially determined by the age factor, normality and bio-psychic integrity, level of affective and regional maturation, flexibility and adaptive plasticity in the conjugal role. At the interpersonal level, marital adaptation aims at the synchronization and complementarity of intercommunication, enhancement and growth of the mutual feelings of affection, as well as of the family affective climate, deepening the partners' acquaintance, stimulating the couple's inter-valorization, balancing and optimizing the sphere of marital actions and decisions, the inter-development of the conjugal-parental roles (Mitrofan, Mitrofan, 1996).

"Marital accommodation or marital inter-accommodation is the mechanism and, at the same time, the process of stimulation and development of marital mutual adaptation. In this interactional process, spouses accept, respect and value each other's interests, attitudes, opinions, habits, values, offering gratifications and support for one another" (Mitrofan, Mitrofan, 1996).

\section{Objectives}

In the process of self-becoming and self-completing, the couple and the family are the path, the means and the chance as a fundamental matrix of life.

In and through the family, man accesses and then incorporates, assimilates and participates to the spiritual, religious, cultural, material values. The conjugal couple expresses structurally and functionally how two people of the opposite sex are creatively shaping each other, developing and complementing each other, through inter-adjustment and fusion, simultaneously at the biological, psychological and social level.

The general object of the research consists of the influence of the psycho-social factors on the duration of the marital couple.

The specific objectives of this study were:

- The identification the marital satisfaction level;

- The study of the factors involved in the functioning and stability of the couple;

- The study of the correlation between the psycho-social factors acting at the couple's level; 


\section{Hypothesis}

Based on the debated thematic and the concepts operationalized in the theoretical part, we formulated the following hypotheses:

$\mathrm{H}_{\mathrm{s} 1}$ - It is assumed that there is a direct link between the duration of the couple and the satisfaction of the spouses.

Hs2 - It is assumed that there is a direct link between the level of marital adjustment and the satisfaction within the couple.

Hs3 - It is assumed that there is an indirect link between the financial situation and the level of conflict.

\section{Participants}

The research was conducted on a sample of 60 subjects, respectively 30 couples. Regarding the structure of the sample, the study participants ranged between 20 to 60 years old.

Table 1. Statistical indicators for age variable

\begin{tabular}{|l|r|}
\hline $\mathrm{N}$ & 60 \\
\hline Mean & 38,18 \\
\hline Median & 36,00 \\
\hline Mode & $28^{\mathrm{a}}$ \\
\hline Minimum & 20 \\
\hline Maximum & 60 \\
\hline $\begin{array}{l}\text { a. Multiple mod exist. The smallest value } \\
\text { is shown. }\end{array}$ \\
\hline
\end{tabular}

The average age of the participants is 38.18 , the median is 36 years old, which means that half of the participants have ages lower than 36, and the other half have more than 36 years old. The age most frequently encountered in the sample is 28 years old, the minimum age being 20 and the maximum being 60, as shown in Table 1.

Based on the couple's duration, we splited the sample into three groups:

- 1-10 years -15 couples,

- 11-20 years -7 couples,

- 21-30 years -8 couples.

The ethics of the research were ensured by obtaining the written consent from all participants who agreed to be part of the study.

\section{Research Instruments}

In this research, four valid instruments were used, through which we could verify the formulated hypotheses: the "Kansas Marital Satisfaction" Test, the "Locke-Wallace Marital Adjustment" Test, the "Kansas Marital Conflict Scale", the "Influence of the Material Situation on the Couple" Questionnaire.

\section{Data Analysis and Interpretation}

\section{Testing hypothesis 1.}


Hs1 - It is assumed that there is a direct link between the duration of the couple and the satisfaction of the spouses.

Table 2. Nonparametric correlations. Spearman: satisfaction and couple duration

\begin{tabular}{l|l|l|r|l}
\hline & & Satisfaction & $\begin{array}{l}\text { Couple } \\
\text { duration }\end{array}$ \\
\hline \multirow{3}{*}{ Spearman's } & \multirow{3}{*}{ Satisfaction } & Correlation & 1,00 &, $29^{*}$ \\
& & Sig. (2-N) & 6 &, 02 \\
& & N & 60 \\
\hline \multirow{5}{*}{ Duration } & Correlation &, $29^{*}$ & 1,00 \\
& & Sig. (2-N) &, 02 & $\cdot$ \\
& & N & 60 & 60 \\
\hline
\end{tabular}

* Correlation is significant at the 0.05 level (2-tiled)

From the correlation analysis we observe that there is a significant positive correlation at a 0.05 level $\left(0.29^{*}\right)$ between satisfaction and the duration of the couple. This positive correlation can be explained by the fact that the higher the satisfaction, the greater the duration of the couple. (The longer the duration of the marriage increases, the greater the satisfaction of the partners).

$\Rightarrow$ Hypothesis 1 is confirmed: there is a direct correlation between the duration of the couple and the satisfaction of the marital partners. The older the couple is, the satisfaction level increases.

\section{Testing hypothesis 2}

Hs2 - It is assumed that there is a direct link between the level of marital adjustment and the satisfaction within the couple.

Table 3. Nonparametric correlations. Spearman: marital adaptation and satisfaction

\begin{tabular}{c|c|l|r|l}
\hline & & & \multicolumn{1}{|c}{$\begin{array}{c}\text { Marital } \\
\text { adjustment }\end{array}$} \\
\hline \multirow{3}{*}{ Spearman's } & Marital & Correlation & 1,000 &, $417^{* *}$ \\
& adjustment & Sig. (2-N) &. &, 02 \\
& N & 60 & 60 \\
\hline \multirow{5}{*}{ Satisfaction } & Correlation &, $417 * *$ & 1,000 \\
& & Sig. $(2-\mathrm{N})$ &, 02 &. \\
& & $\mathrm{~N}$ & 60 & 60 \\
\hline
\end{tabular}

** Correlation is significant at the 0.01 level (2-tiled)

From the correlation analysis we observe that there is a significant positive correlation at a 0.01 level $\left(0.41^{* *}\right)$ between marital adjustment and couple satisfaction. This positive correlation can be explained by the fact that the better the marital adjustment is achieved, the 
greater the satisfaction of the partners will be. The better the couple's partners adapt to the new family model, the more they acquire their marital roles, the greater their satisfaction is.

\section{$\Rightarrow$ Hypothesis 2 is confirmed: there is a direct correlation between the level of marital} adjustment and the satisfaction within the couple.

\section{Testing hypothesis 3}

Hs3 - It is assumed that there is an indirect link between the financial situation and the level of conflict.

Table 4. Nonparametric correlations. Spearman: financial situation and conflict

\begin{tabular}{l|l|l|l|l}
\hline & & $\begin{array}{l}\text { Financial } \\
\text { situation }\end{array}$ & Conflict \\
\hline \multirow{3}{*}{ Spearman's } & $\begin{array}{c}\text { Financial } \\
\text { situation }\end{array}$ & Correlation & 1,000 &,$- 366^{*}$ \\
& Sig. (2-N) &. &, 02 \\
& $\mathrm{~N}$ & 60 & 60 \\
\hline \multirow{5}{*}{ Conflict } & Correlation &,$- 366^{*}$ & 1,000 \\
& Sig. (2-N) &, 02 &. \\
& & 60 & 60 \\
\hline
\end{tabular}

From the correlation analysis in table 21, we observe that there is a negative correlation between the material situation and the conflict level: this means that, as the material situation of the partners that form a couple increases, the level of the conflict decreases and the more the material situation decreases, the level of the conflict increases.

$\rightarrow$ Hypothesis 3 is confirmed: there is an indirect correlation between the financial situation and the level of conflict. As the financial level of the family decreases, the level of conflict increases.

\section{Conclusions}

In the process of self-becoming and self-completing, the couple and the family are the path, the means and the chance as a fundamental matrix of life. In and through the family, individuals access and then incorporate, assimilate and participate in spiritual, religious, cultural, material values. The conjugal couple expresses structurally and functionally how two people of the opposite sex creatively shape each other, developing and complementing each other, through inter-adjustment and fusion, simultaneously at the biological, psychological and social level.

It is difficult to find people with whom you can have satisfactory relationships and with whom you can feel safe, but from the answers of the participants in this study, we can observe that most of them are very satisfied with the marriage they have and only a small part stated that they are somewhat satisfied with their marriage and would like a change in this regard.

In this study we tried to highlight which are the psychosocial factors that influence the duration of the marital couple, while tracking the implications for social services, using for this study both consecrated instruments and our own questionnaire.

In the published literature, many specialists have stated the existence of correlations between certain psychological states and the family situation or environment. Psychological states are mostly influenced by the events that occur around us, in which we are more or less involved. 
The first hypothesis was confirmed by having a direct correlation between the duration of the marital couple and the satisfaction of the marital partners. The longer the duration of the marital couple, the higher the satisfaction level. In the case of older couples, the level of satisfaction is lower. The level of conflict is higher at the beginning of the marriage, due to the failure to adapt to the new family model. The satisfaction of the partners increases in time, by accommodating to the new family model and by overcoming certain problems. Starting from this idea, we formulated the second hypothesis, claiming that there is a direct correlation between marital adjustment and the satisfaction of marital partners. It seems that at the beginning of the marriage, the conjugal partners are not very adapted to the new family model, each trying to impose the origin family model. The satisfaction of the partners is not very high at the beginning of the marriage, many conflicts arising due to the failure to adapt to the new family model. The adjustment of the partners to the couple relationship is very important and contributes to its cohesion: the better the marital adjustment is achieved, the greater the satisfaction of the partners will be. Following research, the hypothesis has been confirmed. In turn, the material situation plays a very important role in the relationship, because a low material situation leads to conflicts between partners, conflicts that once intensified can lead to the dissolution of the couple. The third hypothesis has been confirmed, indeed there is an indirect correlation between the level of conflict and the material situation of the couple. It seems that a precarious economic level most often leads to a high level of conflict. The lower the economic level is, the level of conflict increases. Financial shortcomings most often lead to a family conflict environment.

Numerous problems can occur during marriage. Various psycho-social factors can influence the duration of the marital couple. Knowing the psycho-social factors that influence the marital couple is a measure that must be taken in order to know the functioning mechanisms of the family. Intervention programs cannot be implemented within the family, without knowing them.

In 2008, in one of the European Union countries, many shortcomings persist in the programs aimed at family support. People are not informed about the nature of the offered services, the support they can receive. Also, the acute shortage of specialized personnel is another shortcoming of social programs in our country.

But before the intervention of social services, there must be efforts at the individual level. Each spouse must to some extent try to solve their problems at the family level. Marital failure and disharmony must be understood as an experience of knowledge and development, being transient and resolvable. Awareness of malfunctions and problems is a first step to take in order to solve them. Family life is a game of behavioral solutions.

Through the present paper we have tried to present the psycho-social factors that influence the duration of the marital couple, in order to know the causes that favor a long relationship, and the factors that lead to conflicts or in the worst case, to divorce. For social workers, knowing the family issues is very important. A most effective problem-solving action requires, first and foremost, a thorough knowledge of the mechanisms of the families. But in order to solve family problems, bilateral efforts are needed, both from the conjugal partners and from the social services.

Both the authorities and each individual must act to ensure family support because the family represents the cell of the society, and it must be cultivated for the good of society.

\section{References}

[1] Hooker, K. (2013). Korea, South. In R.E. Emery (Ed.), Cultural Sociology of Divorce. An Encyclopedia. Los Angeles, London, New Delhi, Singapore, Washington DC: SAGE Reference 
[2] Anderson, J. (2014). The impact of family structure on the health of children: Effects of divorce. The Linacre Quarterly, 81(4), pp. 378-387, doi: 10.1179/0024363914Z.00000000087, https://www.ncbi.nlm.nih.gov/pmc/articles/PMC4240051/

[3] Enăchescu, C. (2003). Psychosexology Treaty. Polirom Press, p. 84;

[4] Iolanda Mitrofan, Cuplul conjugal. Armonie şi dizarmonie, Ed. Didacticã şi Pedagogicã, 1989 , Bucureşti

[5] Laird, H. apud. Neamţu, G. (2004). Social Assistance Treaty. Polirom Press, p. 668;

[6] Laird, H. apud. Neamţu, G. (2004). Social Assistance Treaty. Polirom Press, p. 668;

[7] Laman, M. A., Riedman, A. apud. Stan, A. (2005). Family Sociology, Course notes, "Transilvania" University, Braşov, Faculty of Law and Sociology;

[8] Vanier Institute, apud. Baran-Pescaru, A. Family today. A socio-pedagogical perspective, Aramis Press, p. 13;

[9] Baechler, J. apud. Stan, A. (2005). Family Sociology, Course notes, "Transilvania" University, Brasov, Faculty of Law and Sociology;

[10] Mitrofan, I. (1989). The Married Couple. Harmony and Disharmony, Didactic and Pedagogical Press, p. 23;

[11] Popescu-Neveanu, P. (1978). Psychology Dictionary, Albatros Press, p. 262-263;

[12] Iolanda Mitrofan, Cristian Ciupercã, Psihologia vieţii de cuplu, Colectia Alma Mater SPER, 2002

[13] Mihaescu, I., Voinea, M. apud Enache, R. (2008) Family Therapy, Course Notes, "Ovidius" University of Constanta, Faculty of Psychology and Educational Sciences;

[14] Rodica Enache, Terapia familiei, Note de curs , Universitatea „Ovidius” Constanţa 2008, Facultatea de Psihologie şi Ştiintele educatiei

[15] Mitrofan, I., Mitrofan, N. (1996). Elements of couple psychology, Şansa Publishing House, Bucharest; 